\title{
Prevalence of asthma and allergy in Hong Kong schoolchildren: an ISAAC study
}

\author{
R. Leung*, G. Wong**, J. Lau+, A. Ho*, J.K.W. Chan*, D. Choy*, \\ C. Douglass*, C.K.W. Lai*
}

Prevalence of asthma and allergy in Hong Kong schoolchildren: an ISAAC study. R. Leung, G. Wong, J. Lau, A. Ho, J.K.W. Chan, D. Choy, C. Douglass, C.K.W. Lai. ABSTRACT: Asthma and allergic disease in children is increasing in many Western countries but such trend has not been well-defined in Chinese populations. This paper aims to determine the prevalence of asthma and allergic disease in Hong Kong schoolchildren and compare it with previous data to identify a changing trend.

We studied 4,665 schoolchildren aged 13-14 yrs using the International Study of Asthma and Allergy in Childhood (ISAAC) protocol to determine prevalence rates for asthma, wheeze, respiratory symptoms, rhinitis and eczema in 1994-1995. Additional questions on education levels of the parents and smoking status were also asked.

Concordance between responses to the written and video questionnaires was good $(\mathbf{7 6 \%}$ for wheeze ever, $80 \%$ for current wheeze). Prevalence rates for asthma ever, wheeze ever, and current wheeze were 11,20 and $12 \%$, respectively, and were greater in boys $(\mathbf{p}<\mathbf{0 . 0 5})$. Rhinitis affected slightly over half of the subjects $(52 \%)$, and eczema was reported by a sixth $(15 \%)$, whilst current rhinitis and current eczema were present in $44 \%$ and $3.6 \%$ of children, respectively. In multiple logistic regression: odds ratio male sex (OR) 1.47; (95\% confidence interval $(95 \%$ CI) 1.15-1.86); current rhinitis (OR 3.00; 95\% CI 2.36-3.81); current eczema (OR 2.34; 95\% CI 1.40-3.93); and active smoking (OR 2.00; 95\% CI 1.38-2.89) were associated with current wheeze; whilst severe wheezing attack was associated with: current rhinitis (OR 2.72; 95\% CI 1.47-5.02); current eczema (OR 6.13; 95\% CI 2.82-13.33); and active smoking (OR 4.62; 95\% CI 2.43-8.76). Age, parental education and passive smoking were not important factors.

When compared to previous epidemiological data obtained in 1992 , the prevalence rates for asthma ever and wheeze ever had increased by 71 and $255 \%$, respectively, in Hong Kong schoolchildren. The severity of asthma and respiratory symptoms showed a similar increasing trend. Further studies should aim to identify the role of the environment in the pathogenesis of asthma.

Eur Respir J 1997; 10: 354-360.

There is considerable concern over the increase in prevalence of asthma and allergic disease in childhood in Western and developing countries $[1,2]$. Compared to the West, the prevalence of asthma and allergic disease in childhood in South-East Asian populations is lower $[3,4]$, but an increasing trend has also been reported in Taiwan and Japan [4]. In contrast, respiratory ailments in elderly Chinese living in Hong Kong were as common as those reported in Sweden and the USA [5]. Within the Asian Pacific region, marked variation in the prevalence of asthma and allergic disease has been shown, with highest prevalence rates in schoolchildren in Hong Kong, intermediate in Malaysia and lowest rates in China [6]. In another study, approximately $2-4 \%$ of schoolchildren in Hong Kong had severe episodes of wheeze and frequent sleep disturbance due to breathlessness [3]. As one of the participating centres of the International Study of Asthma and Allergy in Childhood (ISAAC), we have surveyed the prevalence of asthma and allergic disease in schoolchildren aged 13-14 yrs in Hong
Depts of *Medicine, **Paediatrics and the Centre for Clinical Trial \& Epidemiological Research, Prince of Wales Hospital, The Chinese University of Hong Kong, Shatin, Hong Kong.

Correspondence: R. Leung

Dept of Medicine

Prince of Wales Hospital

The Chinese University of Hong Kong

Shatin

Hong Kong

Keywords: Allergy

asthma

atopy

Chinese

eczema

epidemiology

schoolchildren

Received: May 101996

Accepted after revision November 241996

The study was supported by Health Services Research Fund 16344050.
Kong using the ISAAC protocol [7], and have compared the results with previous prevalence data in the territory.

\section{Subjects and methods}

Schoolchildren aged 13-14 yrs were targeted for the study following the ISAAC protocol. In participating schools, two school years with the highest proportion of children aged 13-14 yrs were selected for the study and all children in the school class belonging to the respective school years were surveyed. There were a total of 400 secondary schools with approximately 110,000 schoolchildren of the target age range in Hong Kong. Forty of these schools were not eligible for the study, as these schools had less than 100 children in the target age group. The remaining 360 schools were individually allocated a number and, by computer randomization, a list of secondary schools was generated. 
Each school was invited to take part in the study down the order of the school list. Out of the first 15 schools contacted, 13 agreed to participate and were able to provide 4,800 schoolchildren aged 13-14 yrs as potential subjects. These schools were distributed randomly throughout the territory. Written consent was sought from parents and 4,667 agreed to enrol their children in the study, representing a response rate of $97 \%$.

Each subject was given an ISAAC written questionnaire to complete followed by the video questionnaire at the same session in school. The written questionnaire was translated into Chinese following the ISAAC protocol. This involved an independent person who was bilingual and familiar with the use of Cantonese (the dialect in Hong Kong) to translate the original English questionnaire into Chinese. This was then back-translated into English by another bilingual person. The translated questionnaire was tested out in a group of teenagers aged 13-14 yrs, and necessary modifications made before the survey was carried out. During the survey at schools, written questionnaires were completed before the video questionnaires to avoid potential order bias. The ISAAC written questionnaires asked for information on demography, symptoms of wheeze, asthma, rhinitis and eczema. "Current" symptoms referred to symptoms in the past
12 months. Additional questions on active and passive smoking, and parents' education level were also included. The ISAAC international video questionnaire consisted of five scenes displaying young persons of different races (African, Caucasian, Chinese and Indian) with wheeze at rest, wheeze after exercise, night waking with wheeze, night waking with cough and severe asthma attack. The study was conducted between September 1994 and September 1995.

\section{Data analyses}

All data were entered into a computer twice by two independent investigators. Data were categorized and analysed using the statistical package for the social sciences (SPSS) for Windows [8]. The Chi-squared test was used to assess the association between categorical variables. Logistic regression was used to estimate risk factors for current wheeze and severe asthma attack both on written and video questionnaires. Estimates of odds ratios (ORs), standard errors and 95\% confidence intervals (95\% CIs) were based on asymptomatic likelihood theory. A p-value less than 0.05 was considered to be significant.

Table 1. - Response to written questionnaire

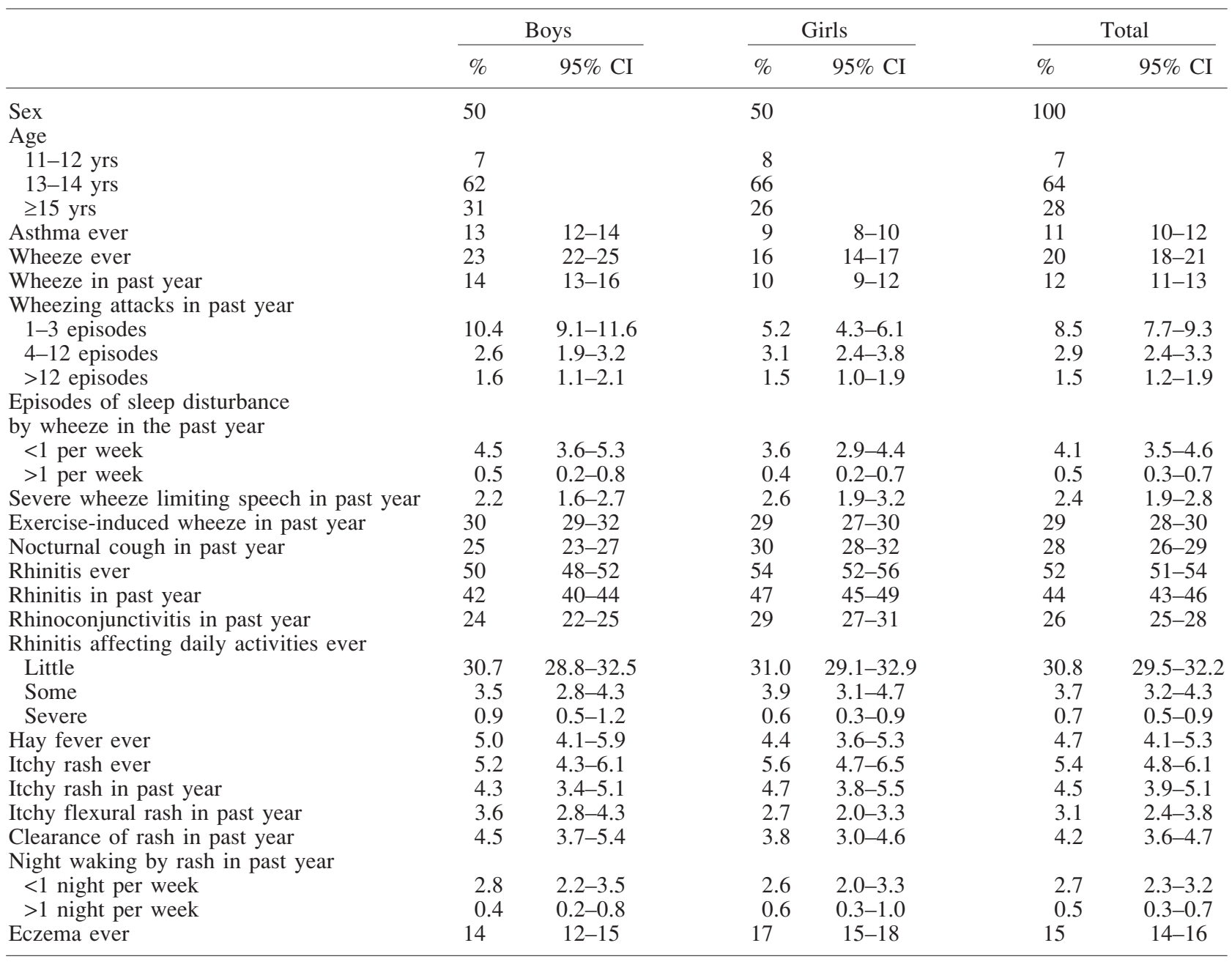

95\% CI: 95\% confidence interval. 


\section{Results}

Table 1 showed the responses to the written questionnaire. Two subjects had missing data on sex and their data were excluded from further analyses, leaving a total of 4,665 children whose data were presented. Asthma ever, wheeze ever and current wheeze were reported by 11,20 and $12 \%$ of schoolchildren, respectively, and the prevalence rates were greater in boys than girls $(\mathrm{p}<0.001)$. Amongst those schoolchildren with current wheeze, $12 \%$ had more than 12 episodes of wheezing attacks and $3.8 \%$ were disturbed by wheeze during sleep at least weekly in the 12 months prior to the survey. Attacks of wheeze severe enough to limit speech in the past 12 months were reported by $2.4 \%$ of respondents, with no sex difference. Current symptoms of exercise-induced wheeze and nocturnal cough were common in both sexes and were noted by 29 and $28 \%$, respectively.

Rhinitis was the most common allergic disease affecting $52 \%$ of subjects and was more common in females $(\mathrm{p}=0.01)$. In particular, it was reported by $70 \%$ of wheezers and $69 \%$ of children with a history of asthma ever. The majority of rhinitis sufferers had perennial symptoms all year round. A total of $707(15 \%)$ of respondents reported eczema ever, but only 156 of them (3.3\%) had an itchy rash affecting the flexural areas in the past 12 months. The number of subjects with current itchy rash $(4.5 \%)$ was similar to those who had lost the symptom in the past year $(4.2 \%)$. Night disturbance by itchy rash was uncommon and affected only $0.5 \%$ of schoolchildren.

Table 2 shows the responses to the video questionnaire. For each of the five respiratory symptoms ascertained, at least two-thirds of respondents who had a history of these symptoms reported symptoms in the past year. Boys complained of more symptoms of wheeze at rest, exercise-induced wheeze and nocturnal wheeze in the past year than girls $(\mathrm{p}<0.05)$, whilst nocturnal cough was more commonly reported by girls $(p<0.001)$. The concordance rates between the two questionnaires were good on symptoms of wheeze ever (76\%) and current wheeze $(80 \%)$ (table 3 ).

Risk factors for current wheeze and severe wheezing attack limiting speech in the past 12 months were calculated by univariate logistic regression (table 4). Boys were more likely to report current wheeze than girls both in written and video questionnaires. Both a history of rhinitis in the past 12 months (or current rhinitis) and itchy rash in the flexural areas in the past 12 months (or current eczema) were associated with current wheeze and severe wheezing attack. Schoolchildren who smoked were twice as likely to have current wheeze and four times more likely to report severe wheezing attack than nonsmokers, as ascertained by the written questionnaire. In a multiple stepwise logistic regression model, the same risk factors remained significant with similar odds ratios for current wheeze by written questionnaire (OR: 1.47 for boys; 3.00 for current rhinitis; 2.34 for current eczema; and 2.00 for active smoking), and severe wheeze by written questionnaire (OR: 2.72 for current rhinitis; 6.13 for current eczema; and 4.62 for active smoking). Age, parental education and passive smoking were not important factors.

Table 3. - Prevalence of lifetime and current wheeze: concordance between the ISAAC written and video* questionnaires

\begin{tabular}{lcrrrr}
\hline \multicolumn{2}{c}{ Questionnaire } & \multicolumn{2}{c}{ Wheeze ever } & \multicolumn{2}{c}{ Wheeze in last year } \\
\multicolumn{2}{l}{ Written } & Video & $\%$ & \multicolumn{1}{c}{$\mathrm{n}$} & \multicolumn{1}{c}{ \% } \\
\hline Yes & Yes & 12 & 546 & 7 & 322 \\
Yes & No & 8 & 365 & 6 & 256 \\
No & Yes & 16 & 765 & 14 & 678 \\
No & No & 64 & 2991 & 73 & 3411 \\
\hline \multicolumn{2}{l}{ Concordance } & 76 & 3537 & 80 & 3733 \\
\hline
\end{tabular}

*: for the video questionnaire, wheezing is defined as a positive response to any of the first three video sequences. ISAAC: International Study of Asthma and Allergy in Childhood.

Table 2. - Responses to video questionnaire

\begin{tabular}{|c|c|c|c|c|c|c|}
\hline & \multicolumn{2}{|c|}{ Boys } & \multicolumn{2}{|c|}{ Girls } & \multicolumn{2}{|c|}{ Total } \\
\hline & $\%$ & $95 \% \mathrm{CI}$ & $\%$ & $95 \% \mathrm{CI}$ & $\%$ & $95 \% \mathrm{CI}$ \\
\hline Wheeze at rest ever & 14.9 & $13.4-16.3$ & 12.4 & $11.1-13.8$ & 13.7 & $12.7-14.6$ \\
\hline Wheeze at rest in past year & 11.1 & $9.8-12.4$ & 8.9 & $7.8-10.1$ & 10.0 & $9.1-10.9$ \\
\hline Wheeze at rest $\geq 1$ per month & 4.2 & $3.4-5.0$ & 3.1 & $2.4-3.8$ & 3.7 & $3.1-4.2$ \\
\hline Wheeze after exercise ever & 24.0 & $22.3-25.8$ & 19.1 & $17.5-20.7$ & 21.5 & $20.4-22.7$ \\
\hline Wheeze after exercise in past year & 17.2 & $15.7-18.8$ & 13.4 & $12.0-14.8$ & 15.3 & $14.3-16.4$ \\
\hline Wheeze after exercise $\geq 1$ per month & 9.4 & $8.2-10.6$ & 7.4 & $6.3-8.5$ & 8.4 & 7.6-9.2 \\
\hline Night waking with wheeze ever & 6.7 & $5.7-7.7$ & 4.4 & $3.5-5.2$ & 5.5 & $4.9-6.2$ \\
\hline Night waking with wheeze in past year & 4.8 & $3.9-5.7$ & 2.8 & $2.1-3.4$ & 3.8 & $3.2-4.3$ \\
\hline Night waking with wheeze $\geq 1$ per month & 1.2 & $0.8-1.7$ & 0.8 & $0.4-1.2$ & 1.0 & $0.7-1.3$ \\
\hline Night waking with cough ever & 26.1 & $24.3-27.9$ & 33.5 & $31.6-35.4$ & 29.8 & $28.5-31.1$ \\
\hline Night waking with cough in past year & 21.8 & $20.1-23.5$ & 27.2 & $25.4-29.0$ & 24.5 & $23.3-25.7$ \\
\hline Night waking with cough $\geq 1$ per month & 4.9 & $4.0-5.7$ & 3.8 & $3.1-4.6$ & 4.4 & $3.8-4.9$ \\
\hline Severe asthma attack ever & 9.7 & $8.5-10.9$ & 9.7 & $8.5-10.9$ & 9.7 & $8.8-10.5$ \\
\hline Severe asthma attack in past year & 6.8 & $5.8-7.8$ & 7.1 & $6.1-8.1$ & 6.9 & $6.2-7.7$ \\
\hline Severe asthma attack $\geq 1$ per month & 2.0 & $1.3-2.8$ & 2.2 & $1.6-2.8$ & 2.1 & $1.7-2.5$ \\
\hline
\end{tabular}

95\% CI: 95\% confidence interval. 
Table 4. - Selected risk factors with odds ratios for current wheeze and severe wheeze limiting speech in the past 12 months by univariate logistic regression

\begin{tabular}{|c|c|c|c|c|c|c|c|c|}
\hline & \multicolumn{4}{|c|}{ Written questionnaire } & \multicolumn{4}{|c|}{ Video questionnaire } \\
\hline & \multicolumn{2}{|c|}{ Current wheeze } & \multicolumn{2}{|c|}{ Severe attack } & \multicolumn{2}{|c|}{ Current wheeze } & \multicolumn{2}{|c|}{ Severe attack } \\
\hline & OR & $95 \% \mathrm{CI}$ & OR & $95 \% \mathrm{CI}$ & OR & $95 \% \mathrm{CI}$ & OR & $95 \% \mathrm{CI}$ \\
\hline \multicolumn{9}{|l|}{ Age } \\
\hline $11-12$ yrs & 1.00 & - & 1.00 & - & 1.00 & - & 1.00 & - \\
\hline $13-14$ yrs & 1.08 & $0.77-1.53$ & 0.86 & $0.42-1.74$ & 1.00 & $0.69-1.49$ & 0.91 & $060-1.37$ \\
\hline$>14$ yrs & 1.11 & $0.77-1.60$ & 1.02 & $0.48-2.14$ & 1.08 & $0.73-1.60$ & 0.80 & $0.51-1.26$ \\
\hline \multicolumn{9}{|l|}{ Sex } \\
\hline Female & 1.00 & - & 1.00 & - & 1.00 & - & 1.00 & - \\
\hline Male & 1.42 & $1.19-1.70$ & 0.84 & $0.57-1.22$ & 1.27 & $1.05-1.54$ & 0.95 & $0.76-1.20$ \\
\hline \multicolumn{9}{|c|}{ Rhinitis in past year } \\
\hline No & 1.00 & - & 1.00 & - & 1.00 & - & 1.00 & - \\
\hline Yes & 3.07 & $2.55-3.70$ & 2.90 & $1.93-4.37$ & 2.23 & $1.83-2.71$ & 2.28 & $1.81-2.88$ \\
\hline \multicolumn{9}{|c|}{$\begin{array}{l}\text { Itchy flexural rash in } \\
\text { past year }\end{array}$} \\
\hline No & 1.00 & - & 1.00 & - & 1.00 & - & 1.00 & - \\
\hline Yes & 2.93 & $2.04-4.19$ & 7.14 & $4.28-11.93$ & 2.62 & $1.77-3.88$ & 3.89 & $2.60-5.82$ \\
\hline \multicolumn{9}{|c|}{ Father's education } \\
\hline$\leq$ Form 3 & 1.00 & - & 1.00 & - & 1.00 & - & 1.00 & - \\
\hline Form 4-7 & 1.03 & $0.80-1.31$ & 1.15 & $0.66-2.01$ & 1.26 & $0.96-1.63$ & 1.09 & $0.78-1.53$ \\
\hline$\geq$ College & 1.27 & $0.94-1.72$ & 1.04 & $0.49-2.21$ & 0.96 & $0.66-1.38$ & 1.44 & $0.96-2.15$ \\
\hline \multicolumn{9}{|c|}{ Mother's education } \\
\hline$\leq$ Form 3 & 1.00 & - & 1.00 & - & 1.00 & - & 1.00 & - \\
\hline Form 4-7 & 1.17 & $0.93-1.49$ & 1.13 & $0.65-1.99$ & 1.24 & $0.96-1.61$ & 1.43 & $0.95-1.95$ \\
\hline$\geq$ College & 1.33 & $0.89-1.99$ & 2.05 & $0.93-4.51$ & 1.19 & $0.75-1.89$ & 1.38 & $0.80-2.40$ \\
\hline \multicolumn{9}{|c|}{ Active smoking } \\
\hline No & 1.00 & - & 1.00 & - & 1.00 & - & 1.00 & - \\
\hline Yes & 1.98 & $1.39-2.82$ & 4.15 & $2.25-7.68$ & 1.31 & $0.85-2.01$ & 1.07 & $0.61-1.88$ \\
\hline \multicolumn{9}{|c|}{ Passive smoking } \\
\hline No & 1.00 & - & 1.00 & - & 1.00 & - & 1.00 & - \\
\hline Yes & 1.14 & $0.92-1.42$ & 1.05 & $0.64-1.74$ & 0.96 & $0.76-1.23$ & 0.97 & $0.72-1.31$ \\
\hline
\end{tabular}

OR: odds ratio; 95\% CI: 95\% confidence interval.

\section{Discussion}

Phase I of ISAAC uses core questionnaires to assess the prevalence and severity of asthma and allergic disease in defined populations. The data collection is based on both written and video questionnaires. Although the assessment of childhood respiratory symptoms by questionnaires is largely accurate and reproducible [9], the use of written questionnaires may not allow reliable comparisons of asthma prevalence among populations from different cultures or speaking different languages. Video questionnaire, consisting of scenes of children displaying signs of asthma, has been shown to be more reproducible than written questionnaire [10]. It also has similar sensitivity and specificity with respect to bronchial hyperresponsiveness when compared to standard questionnaires in Caucasian schoolchildren [10]. In a validation study of the ISAAC international video questionnaire against bronchial responsiveness to methacholine, it was found that the video questionnaire had similar sensitivity and specificity to the ISAAC written questionnaire [11]. A satisfactory concordance on the prevalence rates of lifetime and current wheeze was also seen between the written and video questionnaire. Despite the inevitable recall bias inherent in cross-sectional questionnaire surveys and the lack of objective laboratory measures in the present study, we believe the prevalence rates of respiratory symptoms obtained were representative of secondary schoolchildren in Hong Kong.
The results of the present study show that the prevalence rates of some respiratory symptoms were higher in boys than girls. This male predominance is in keeping with previous data from the territory [3], but a reverse sex ratio has been shown in preliminary ISAAC data from other centres in Western populations [12]. In the National Child Development Study in the UK, where over 17,000 children were followed from birth to 23 yrs, a male predominance in the incidence of asthma was seen up to $16 \mathrm{yrs}$ and the sex ratio reversed thereafter [13]. The explanation for the reversal in sex ratio during adolescence is unclear, but is not thought to be related to hormonal changes at that time. A recent study in New Zealand found that the higher prevalence of asthma in boys aged 13 yrs was partly due to a higher rate of sensitization to indoor allergens than their female counterparts, as assessed by skin-prick tests [14]. It is possible that atopy was more common in boys than girls in the present study, but skin-prick tests were not performed. A previous study of asthma and allergy in children in the territory did not show any gender difference in skin test positivity [6], but in adult asthmatics, atopy rate was $20 \%$ higher in males than females [15]. The higher prevalence of asthma in boys could also be due to their smaller airways relative to lung size than girls [16]. However, when only severe respiratory symptoms, such as severe wheeze limiting speech and wheeze with sleep disturbance, were considered in the present cohort, the sex difference became less obvious and even 
disappeared. Although the exact mechanisms underlying these observations are unclear, one possible explanation could be that boys tend to underestimate whilst girls tend to overestimate the severity of their disease.

The association of allergic rhinitis and eczema with childhood asthma is well-known and is a characteristic feature of the atopic trait [17]. We used itchy flexural rash in the logistic regression model, as this is an appropriate measure of intermittent disease characteristic of atopic dermatitis and avoids the diagnostic label of "eczema", which might reflect accessibility of doctors, and other cultural and socioeconomic bias in reporting [18]. Children with a history of eczema at the age of 7 yrs have been shown to be more likely to have persistent asthma from early childhood throughout adolescence and into adult life [19].

When the ISAAC data were compared to a previous survey of asthma and allergic disease in South-East Asian children in 1992 [6], the prevalence rates for asthma ever and wheeze ever in Hong Kong had increased by 71 and $255 \%$, respectively (table 5). One explanation for the marked increase in prevalence was inevitably due to differences in study design and questionnaires between the two studies. In the previous study, a Chinese version of the Monash Respiratory Questionnaire [20] was completed by the parents of participating schoolchildren. When results of the current study were compared to another study in 1992 [3], which involved parental completion of a respiratory questionnaire similar to ISAAC, the frequency and severity of respiratory symptoms showed a similar increase. However, in a separate study of university students in 1989 and 1994 using the same written questionnaire, our group has previously shown that a history of asthma ever and current wheeze increased from 4.8 to $7.2 \%$ and 4.6 to $7.6 \%$, respectively [4], indicating that the rise in asthma prevalence was unlikely to be due to difference in the questionnaire used. Increased community awareness of asthma and allergy in recent years, due partly to active public campaigns by local medical bodies, is likely to contribute to the change in disease prevalence but its extent is difficult to measure. Nevertheless, the rise in asthma prevalence together with other allergic disease over such a short period of time may also reflect a broadly based change in reactivity, possibly due to increased exposure to allergens and other environmental factors.

Seven percent of the children in the present study were active smokers and those who regularly smoked were more likely to report current wheeze and severe asthma attack than nonsmokers. Whilst active smoking may increase the risk of developing occupational asthma to acid anhydrides [21], and several prospective studies of adults have confirmed an increased risk of physician-diagnosed asthma in current smokers [22, 23], there are few data on the effect of active smoking on childhood asthma. In a study of risk factors for bronchial hyperresponsiveness in children aged 7-16 yrs, active smoking had no influence on the degree of airway hyperreactivity [24]. Assessment of smoking status based on self-reporting alone is neither sensitive nor specific. Using serum cotinine level as a surrogate biochemical marker for cigarette smoking, a recent study of 743 Mexican American adults showed that $6.3 \%$ of self-reported nonsmokers were found to be biochemical smokers, whereas up to $12.1 \%$ of self-reported smokers were found to have low levels of cotinine in the serum [25].

On the other hand, passive smoking by parental reporting has been widely-implicated in the development of bronchial hyperresponsiveness [26], development [27] and exacerbation of asthma [28], as well as recurrent wheezing [29] in susceptible children. The assessment of passive smoking in the present study was based entirely on questionnaire response to the question "Are there any members of you family who smoke in the home?", and no association was found between passive smoking and respiratory symptoms in schoolchildren. This could be partly explained by the unawareness and, hence, underestimation by the schoolchildren of parental smoking during the most susceptible periods in infancy and early childhood. Alternatively, as only $3 \%$ of females in Hong Kong are active smokers and maternal smoking confers a greater risk of respiratory illness than paternal smoking, the lack of association between passive smoking and respiratory symptoms in this study could be due to low level of maternal smoking. Some epidemiological studies have found a negative correlation between active cigarette smoking and respiratory symptoms suggestive of asthma [30]; this was thought to reflect smoking cessation or avoidance by individuals with sensitive airways rather than a protective effect on asthma by smoking.

The association between asthma prevalence and socioeconomic class was controversial, with some studies showing positive correlation [31], whilst others showed no relation [32] and even negative correlation [33]. Proponents for the claim that asthma is more prevalent in

Table 5. - Prevalence (\%) of asthma and allergic disease in schoolchildren in Hong Kong in 1992 and 1995

\begin{tabular}{|c|c|c|c|}
\hline & $\begin{array}{c}1992 \\
(\mathrm{n}=1,062)^{*}\end{array}$ & $\begin{array}{c}1992 \\
(\mathrm{n}=1,170)^{\dagger}\end{array}$ & $\begin{array}{c}1995 \\
(n=4,665)\end{array}$ \\
\hline Age range yrs & $12-16$ & $12-15$ & $13-14$ \\
\hline M:F ratio & 1.35 & 1.12 & 0.99 \\
\hline Asthma ever & $6.6 \quad(5.1-8.1)$ & $7.9 \quad(6.4-9.4)$ & $11.2(10.3-12.1)$ \\
\hline Wheeze ever & $(6.2-9.4)$ & $(8.6-12.0)$ & $19.5(18.3-20.6)$ \\
\hline Wheeze in past year & $(2.6-4.8)$ & $(3.1-5.5)$ & $12.4(11.5-13.3)$ \\
\hline Rhinitis ever & 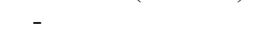 & & $53 \quad(52-54)$ \\
\hline Eczema ever & $(18-22)$ & & $(14-16)$ \\
\hline Sleep disturbance by wheeze in past year & & $(2.0-4.0)$ & $(4.0-5.2)$ \\
\hline Exercise induced wheeze in past & & $(14-18)$ & $(28-30)$ \\
\hline Nocturnal cough in past year & & $(9-13)$ & $(26-29)$ \\
\hline
\end{tabular}

M: male; F: female. *: data from [6]; †: data from [3]. 
children of parents of lower social class often attribute the high asthma prevalence and asthma hospitalization rates to inadequate access and utilization of medical services by the poor [3]. Parents of asthmatic children, particularly mothers in Chinese populations play an important role in the day-to-day asthma management at home. It is plausible that a low maternal education level can lead to poor awareness and, hence, poor understanding of asthma and its appropriate management, resulting in underrecognition and undertreatment of asthma symptoms. However, the present data did not demonstrate an association between asthma symptoms and parental education level. It has been suggested that education level alone is not a sensitive marker of socioeconomic class as it is stable once achieved and does not pick up change in social class after leaving school [34].

When the present results were compared to the ISAAC data of 13-14 year olds from Beijing and Guangzhou, a trend towards higher prevalence of asthma and allergic disease in affluent communities was clearly evident, with Hong Kong having the highest prevalence rates of these diseases [35]. This is consistent with the findings of higher prevalence of asthma, allergies and atopy amongst West Germany schoolchildren compared to East Germany [36]. Which components of affluent living can account for the regional variation in asthma prevalence in our locality and what environmental factors in Hong Kong can explain the rapid increase in prevalence of asthma and allergic disease remain largely unknown.

As children spend most of their time indoors, environmental factors at home are considered important pathogenetic factors for asthma and allergies. These may include allergic sensitization to indoor inhalant allergens, exposure to air pollutants, diet and other, as yet unidentified, factors. Data collection for ISAAC Phase I study is near its completion and over 35 countries worldwide, comprising more than 120 centres, have provided information on the global trend in prevalence and severity of asthma and allergies. The Phase II study aims to assess differences between populations with contrasting Phase I data in terms of indoor environment, lifestyle and medical care. It is envisaged that in ISAAC Phase II, the pathogenic role of the environment can be objectively studied and individual factors carefully assessed to provide valuable information, which may explain the global distribution and increasing trend of asthma and allergies today.

Acknowledgements: The authors wish to thank M. Tong, A. Chan and A. Cheung for their technical support.

\section{References}

1. Robertson $\mathrm{CH}$, Heycock E, Bishop J, Nolan T, Olinsky A, Phelan PD. Prevalence of asthma in Melbourne schoolchildren: change over 26 years. BMJ 1991; 302: 11161118.

2. Ninan TK, Russell G. Respiratory symptoms and atopy in Aberdeen schoolchildren: evidence from two surveys 25 years apart. BMJ 1992; 304: 873-875.

3. Leung R, Bishop J, Robertson C. Prevalence of asthma and wheeze in Hong Kong schoolchildren. Eur Respir J 1994; 7: 2046-2049.
4. Lai CKW, Douglass C, Ho SS, et al. Asthma epidemiology in the far east. Clin Exp Allergy 1996; 26: 5-12.

5. Lai CKW, Ho SC, Lau J, et al. Respiratory symptoms in elderly Chinese living in Hong Kong. Eur Respir $J$ 1995; 8: 2055-2061.

6. Leung R, Ho P. Asthma, allergy and atopy in three south-east Asian populations. Thorax 1994; 49: 12051210.

7. Asher MI, Keil U, Anderson HR, et al. International study of asthma and allergies in childhood (ISAAC): rationale and methods. Eur Respir J 1995; 8: 483-491.

8. $\quad$ SPSS for Windows Release 6.0. Maija J Norusis/SPSS Inc. 1993.

9. Brunekreef B, Groot B, Rijcken B, Hoek G, Steenbekkers A, de Boer A. Reproducibility of childhood respiratory symptom questions. Eur Respir J 1992; 5: 930-935.

10. Shaw RA, Crane J, Pearce NE, et al. Validation of a video questionnaire for assessing asthma prevalence. Clin Exp Allergy 1992; 22: 561-568.

11. Lai CKW, Chan JKW, Wong G, et al. Comparison of the ISAAC video questionnaire (AVQ3.0) with the ISAAC written questionnaire for estimating asthma prevalence. Clin Exp Allergy 1996; (In Press).

12. Pearce N, Weiland S, Keil U, et al. Self-reported prevalence of asthma symptoms in children in Australia, England, Germany and New Zealand: an international comparison using the ISAAC protocol. Eur Respir $J$ 1993; 6: 1455-1461.

13. Anderson HR, Pottier AC, Strachan DP. Asthma from birth to age 23: incidence and relation to prior and concurrent atopic disease. Thorax 1992; 47: 537-542.

14. Sears MR, Burrows B, Flannery EM, Herbison GP, Holdaway MD. Atopy in childhood. I. Gender and allergen-related risks for development of hay fever and asthma. Clin Exp Allergy 1993; 23: 941-948.

15. Leung R, Lam CWK, Ho A, Chan JKW, Choy D, Lai CKW. Allergic sensitisation to common environmental allergens in adult asthmatics in Hong Kong. Hong Kong Med J 1996; (In Press).

16. Tepper RS, Morgan WJ, Cota K, Wright A, Taussig LM, GHMA Pediatricians. Physiologic growth and development of the lung during the first year of life. Am Rev Respir Dis 1986; 134: 513-519.

17. Anderson HR, Pottier AC, Strachan DP. Asthma from birth to age 23: incidence and relation to prior and concurrent atopic disease. Thorax 1992; 47: 537-542.

18. Williams HC, Burney PGJ, Hay RJ, et al. The UK Working Party's Diagnostic criteria for atopic dermatitis. I. Derivation of a minimum set of discriminators for atopic dermatitis. Br J Dermatol 1994; 131: 383-396.

19. Jenkins MA, Hopper JL, Bowes G, Carlin JB, Flander LB, Giles GG. Factors in childhood as predictors of asthma in adult life. BMJ 1994; 309: 90-93.

20. Abramson M, Kutin J, Bowes G. The prevalence of asthma in Victoria adults. Aust NZ J Med 1992; 22: 358-363.

21. Venables KM Topping MD, Howe $\mathrm{W}$, et al. Interaction of smoking and atopy in producing specific IgE antibody against a hapten protein conjugate. $\mathrm{Br}$ Med J 1985; 290: 201-204.

22. Vesterinen E, Kaprio J, Koskenvuo M. Prospective study of asthma in relation to smoking habits among 14,729 adults. Thorax 1988; 43: 534-539.

23. Krzyzanowski M, Lebowitz MD. Changes in chronic respiratory symptoms in two populations of adults studied longitudinally over 13 years. Eur Respir J 1992; 5: 12-20.

24. Backer V, Groth S, Dirksen A, et al. Sensitivity and 
specificity of the histamine challenge test for the diagnosis of asthma in an unselected sample of children and adolescents. Eur Respir J 1991; 4: 1093-1100.

25. Perez-Stable EJ, Marin G, Marin BV, Benowitz NL. Misclassification of smoking status by self-reported cigarette consumption. Am Rev Respir Dis 1992; 145: 5357.

26. Forastiere F, Agabiti N, Corbo GM, et al. Passive smoking as a determinant of bronchial responsiveness in children. Am J Respir Crit Care Med 1994; 149: 365-370.

27. Martinez FD, Cline M, Burrows B. Increased incidence of asthma in children of smoking mothers. Paediatrics 1992; 89: 21-26.

28. Chilmonczyk BA, Salmun LM, Megathlin KN, et al. Association between exposure to environmental tobacco smoke and exacerbations of asthma in children. $N$ Engl J Med 1993; 328: 1665-1669.

29. Henderson FW, Henry MM, Ivins SS, et al. Correlates of recurrent wheezing in school-age children. Am J Respir Crit Care Med 1995; 151: 1786-1793.

30. Trosi RJ, Speizer FE, Rosner B, Trichopoulos D, Willett WC. Cigarette smoking and incidence of chronic bronchitis and asthma in women. Chest 1995; 108: 1557-1561.
31. Halfon N, Newacheck PW. Childhood asthma and poverty: differential impacts and utilization of health services. Paediatrics 1993; 91: 56-61.

32. Mitchell EA, Stewart AW, Pattemore PK, Asher MI, Harrison AC, Rea HH. Socioeconomic status in childhood asthma. Int J Epidemiol 1989; 18: 888-890.

33. Peat JK, Woolcock AJ, Leeder SR, Blackburn RB. Asthma and bronchitis in Sydney schoolchildren. II. The effect of social factors and smoking on prevalence. $\mathrm{Am}$ $J$ Epidemiol 1980; 111: 728-735.

34. Ernst P, Demissie K, Joseph L, Locher U, Becklake MR. Socioeconomic status and indicators of asthma in children. Am J Respir Crit Care Med 1995; 152: 570-575.

35. Lai CKW, Chen YZ, Zhong NS, et al. Comparison of prevalence of asthma symptoms, allergic rhinitis and eczema in Chinese children using the International Study of Asthma and Allergies in Childhood (ISAAC) protocol (Abstract). Am J Respir Crit Care Med 1996; 135; A856.

36. Von Mutius E, Martinez FD, Fritzsch C, Nicolai T, Roell G, Thiemann H-H. Prevalence of asthma and atopy in two areas of West and East Germany. Am J Respir Crit Care Med 1994; 149: 358-364. 